\title{
EFFECT OF BREAST CANCER ON PHYSICAL ACTIVITY IN WOMEN
}

\author{
PAWE€ KALINOWSKI ${ }^{1}$, URSZULA BOJAKOWSKA ${ }^{1,2}$, MARTA KOWALSKA ${ }^{1}$ \\ ${ }^{1}$ Medical University of Lublin, Faculty of Health Sciences, Independent Epidemiology Unit \\ ${ }^{2}$ Student Research Group, Medical University of Lublin, Faculty of Health Sciences, \\ Independent Epidemiology Unit
}

\author{
Mailing address: Urszula Bojakowska, Medical University of Lublin, Independent Epidemiology Unit, \\ 4/6 Staszica Street, 20-081 Lublin, tel.: +48 81 4486942, fax: +48 81 4486700, e-mail: urszula.bojakowska@umlub.pl
}

\begin{abstract}
Introduction. Breast cancer is the most commonly found type of cancer in women. One cancer risk factor related to lifestyle that seems to be particularly worth examining is physical activity. The aims of the study were to analyse the physical activity of women who had been diagnosed with breast cancer for the first time and had undergone surgical treatment as well as to determine how their physical activity patterns changed with respect to the patterns from before the diagnosis. Material and methods. The research was carried out by means of a diagnostic survey. The instrument used was an original questionnaire designed for the purposes of the study. A total of 200 female breast cancer patients were surveyed between September 2015 and April 2016. The data collected in the study were subjected to statistical analysis. Results. The study showed that after developing cancer, a considerable percentage of women who were not physically active earlier started to perform regular physical activity. Before being diagnosed with cancer, 58\% of the respondents did not spend any time engaging in physical activity or only performed it up to 30 minutes per week, whereas after receiving the diagnosis, more than half of the respondents spent a few hours a week being physically active. Conclusions. After being diagnosed with breast cancer, the majority of patients led a healthy lifestyle; the women surveyed in the study were more active and spent more time engaging in sports and recreation.
\end{abstract}

Key words: physical activity, breast cancer, women, lifestyle

\section{Introduction}

Breast cancer is the most frequently diagnosed type of cancer among women. According to the data of the World Health Organization, in 2012, 1.67 million new cases of the disease were diagnosed, which accounted for $25.2 \%$ all cancers in women. The disease caused 522,000 deaths, that is $14.7 \%$ of all cancerrelated deaths in women [1-3]. The pathogenesis of breast cancer is influenced by many factors; however, the direct cause of this type of cancer remains unknown. The epidemiological research conducted so far has shown that the main factors responsible for causing cancer are behavioural in nature [4-6]. Among the many cancer risk factors, two factors which should be given particular attention are the lack of physical activity and the consumption of nutritionally imbalanced meals. These aspects of lifestyle are not only major risk factors for many diseases, but they also have an impact on physical and mental capacity and well-being. It is worth noting that the lifestyle of women diagnosed with breast cancer can cause them to develop cancer and also help them return to full activity after receiving treatment.

The role of physical activity in the etiology of breast cancer has been the subject of many research studies, and most of them have shown that the risk of developing breast cancer is lower in women who are physically active. This risk was reduced by $30 \%$ to $40 \%$ for women who were most active compared to those who had a sedentary lifestyle [7]. Recreational activity can reduce the risk of developing breast cancer as well, as can moderateand high-intensity physical activity in the form of housework. However, the relationship between breast cancer and physical activity still requires exploration with respect to determining the type and intensity of this activity and the period in women's lives when it can have the greatest preventive effect [8]. Some studies have demonstrated that increased physical activity in the post-menopausal period helped women reduce the risk of developing breast cancer. This finding is likely related to the fact that physically active women have reduced BMI and estrogen levels [9]. High levels of physical activity probably cause a decrease in breast cancer risk by inhibiting ovary function (and thus reducing estrogen production) [10].

The aims of the study were to analyse the physical activity of women who had been diagnosed with breast cancer for the first time and had undergone surgical treatment as well as to determine how their physical activity patterns changed with respect to the patterns from before the diagnosis.

\section{Material and methods}

The study was carried out between September 2015 and April 2016. The participants were female cancer patients who had undergone surgery and who had been diagnosed with cancer for the first time. All the subjects consented to participate in the study. Any respondents who did not meet the criteria for being included in the study were excluded from it. The subjects were patients of the Surgical Oncology Ward of the Provincial Specialist Hospital in Lublin and members of the Amazons Association (breast cancer survivor association) in the Lublin Province. Before the study was launched, approval was obtained from the head of the Provincial Specialist Hospital in Lublin, 
the head of the Surgical Oncology Ward, and the president of the Amazons Association in the Lublin Province as well as from the Bioethics Committee of the Medical University of Lublin (Approval No. KE-0254/45/2015).

The data were collected by means of a diagnostic survey. In order to examine the physical activity of the respondents and determine the changes in their physical activity with respect to patterns from before the diagnosis, an original questionnaire was designed. The questionnaire consisted of 74 questions which concerned the women's socio-demographic characteristics as well as selected elements of their lifestyle. Some of the questions probed the respondents' subjective evaluation of their lifestyle, physical activity, time spent engaging in physical activity, and leisure time activity both before and after the cancer diagnosis. The main study was preceded by a pilot study, which was carried out on a group of 30 breast cancer patients with the aim of verifying the research instrument. A total of 200 breast cancer patients were surveyed.

The data were subjected to statistical analysis with the use of the STATISTICA data analysis software system (StatSoft, Inc., 2011), version 10. The socio-demographic characteristics of the respondents were presented using descriptive statistics. The associations between selected variables were analysed using the Wilcoxon signed-rank test. Statistical significance was set at $\mathrm{p}<0.05$.

\section{Results}

The study involved 200 breast cancer patients. The mean age of the respondents was 63.0 years, with a standard deviation

Table 1. Participant characteristics

\begin{tabular}{|c|c|c|c|}
\hline \multicolumn{4}{|c|}{ Socio-demographic data N \% } \\
\hline \multirow{6}{*}{ Age } & $30-39$ & 2 & $1.0 \%$ \\
\hline & $40-49$ & 11 & $5.5 \%$ \\
\hline & $50-59$ & 49 & $24.5 \%$ \\
\hline & $60-69$ & 100 & $50.0 \%$ \\
\hline & $70-79$ & 35 & $17.5 \%$ \\
\hline & $80-89$ & 3 & $1.5 \%$ \\
\hline \multirow{3}{*}{ Place of residence } & Countryside & 26 & $13.0 \%$ \\
\hline & $\begin{array}{c}\text { Small city } \\
(\leq 50,000 \text { inhabitants })\end{array}$ & 72 & $36.0 \%$ \\
\hline & $\begin{array}{c}\text { Large city } \\
(>50,000 \text { inhabitants })\end{array}$ & 102 & $51.0 \%$ \\
\hline \multirow{4}{*}{ Education } & Primary & 3 & $1.5 \%$ \\
\hline & Vocational & 30 & $15.0 \%$ \\
\hline & Secondary & 124 & $62.0 \%$ \\
\hline & Higher & 43 & $21.5 \%$ \\
\hline \multirow{4}{*}{ Marital status } & Unmarried & 10 & $5.0 \%$ \\
\hline & Married & 115 & $57.5 \%$ \\
\hline & Divorced & 22 & $11.0 \%$ \\
\hline & Widowed & 53 & $26.5 \%$ \\
\hline \multirow{4}{*}{ Financial situation } & Very good & 4 & $2.0 \%$ \\
\hline & Good & 54 & $27.0 \%$ \\
\hline & Average & 125 & $62.5 \%$ \\
\hline & Poor & 17 & $8.5 \%$ \\
\hline
\end{tabular}

of 8.3 years. The youngest respondent was 35 years old, and the oldest one was 87 years old. Patients aged 60-69 years were the most numerous, and the second largest age group in the sample was 50- to 59-year-olds. Most of the respondents lived in a large city. The majority of them had secondary education, a smaller group had higher education, and fewer respondents had completed vocational education. When it comes to the respondents' marital status, most of them were married, and widowed women were the second largest group. The women typically regarded their financial situation as average (Tab. 1).

The first part of the analysis focused on determining the lifestyle of the breast cancer patients. An analysis carried out using the Wilcoxon signed-rank test showed that the women's lifestyle after the diagnosis differed significantly $(\mathrm{p}<0.05)$ from that before the diagnosis. Most patients declared that they led a healthy lifestyle after being diagnosed with cancer. Among those who already had a healthy lifestyle before the diagnosis, $72 \%$ maintained it after the diagnosis. As for those who did not have a healthy lifestyle before they were diagnosed, almost half $(48.6 \%)$ changed their lifestyle to a healthy one when they found out they had cancer (Tab. 2).

The study showed that after being treated for cancer, a considerable percentage of women who did not perform sports or other physical activity earlier started being regularly physically active. In the group of women who were physically active before developing cancer, more than half continued to engage in sports or other physical activity, whereas the remaining women restricted their physical activity. Among women who declared that they were physically active only occasionally before receiving the cancer diagnosis, as many as $35.7 \%$ started practising sports regularly after being diagnosed. According to the results of the analysis carried out using the Wilcoxon signed-rank test, the differences between the respondents' sports and other physical activity before and after the diagnosis were statistically significant ( $\mathrm{p}<0.05)$ (Tab. 3).

An analysis of the time the respondents spent engaging in physical activity before and after being diagnosed with cancer also revealed a significant difference $(\mathrm{p}<0.05)$. Before developing cancer, $58 \%$ of the respondents did not spend any time performing physical activity or only engaged in it up to 30 minutes per week, while after being diagnosed with cancer, more than

Table 2. Lifestyle after cancer diagnosis depending on lifestyle before diagnosis

\begin{tabular}{|c|c|c|c|c|c|c|c|c|c|}
\hline \multirow{3}{*}{$\begin{array}{l}\text { Healthy } \\
\text { life- } \\
\text { style }\end{array}$} & \multirow{2}{*}{\multicolumn{2}{|c|}{$\begin{array}{c}\text { Before } \\
\text { diagnosis }\end{array}$}} & \multicolumn{6}{|c|}{ After diagnosis } & \multirow{3}{*}{$\begin{array}{l}\text { Wilcoxon } \\
\text { signed- } \\
\text { rank test }\end{array}$} \\
\hline & & & \multicolumn{2}{|c|}{ Yes } & \multicolumn{2}{|r|}{ No } & \multicolumn{2}{|c|}{$\begin{array}{l}\text { I don't } \\
\text { know }\end{array}$} & \\
\hline & $\mathrm{N}$ & $\%$ & $\mathrm{~N}$ & $\%$ & $\mathrm{~N}$ & $\%$ & $\mathrm{~N}$ & $\%$ & \\
\hline Yes & 50 & $25.0 \%$ & 36 & $72.0 \%$ & 1 & $2.0 \%$ & 13 & $26.0 \%$ & \multirow{4}{*}{$\begin{array}{c}Z=6.91 \\
p<0.0001\end{array}$} \\
\hline No & 72 & $36.0 \%$ & 35 & $48.6 \%$ & 10 & $13.9 \%$ & 27 & $37.5 \%$ & \\
\hline $\begin{array}{l}\text { I don't } \\
\text { know }\end{array}$ & 78 & $39.0 \%$ & 33 & $42.3 \%$ & 6 & $7.7 \%$ & 39 & $50.0 \%$ & \\
\hline \multicolumn{3}{|c|}{ Total } & 104 & $52.0 \%$ & 17 & $8.5 \%$ & 79 & $39.5 \%$ & \\
\hline
\end{tabular}


Table 3. Sports and other physical activity after cancer diagnosis depending on activity before diagnosis

\begin{tabular}{|c|c|c|c|c|c|c|c|c|c|c|c|}
\hline \multirow{3}{*}{$\begin{array}{l}\text { Sports and other } \\
\text { physical activity }\end{array}$} & \multicolumn{2}{|c|}{ Before diagnosis } & \multicolumn{8}{|c|}{ After diagnosis } & \multirow{3}{*}{$\begin{array}{c}\text { Wilcoxon } \\
\text { signed-rank tes }\end{array}$} \\
\hline & \multirow[t]{2}{*}{$\mathbf{N}$} & \multirow[t]{2}{*}{$\%$} & \multicolumn{2}{|c|}{ Competitive } & \multicolumn{2}{|c|}{$\begin{array}{l}\text { Systematic, } \\
\text { for pleasure }\end{array}$} & \multicolumn{2}{|c|}{ Occasional } & \multicolumn{2}{|c|}{ None } & \\
\hline & & & $\mathbf{N}$ & $\%$ & $\mathbf{N}$ & $\%$ & $\mathbf{N}$ & $\%$ & $\mathbf{N}$ & $\%$ & \\
\hline Competitive & 4 & $2.0 \%$ & 1 & $25.0 \%$ & 0 & $0.0 \%$ & 2 & $50.0 \%$ & 1 & $25.0 \%$ & \multirow{5}{*}{$\begin{array}{c}Z=3.96 \\
p=0.0001\end{array}$} \\
\hline Systematic, for pleasure & 32 & $16.0 \%$ & 1 & $3.1 \%$ & 18 & $56.3 \%$ & 11 & $34.4 \%$ & 2 & $6.3 \%$ & \\
\hline Occasional & 98 & $49.0 \%$ & 1 & $1.0 \%$ & 34 & $34.7 \%$ & 49 & $50.0 \%$ & 14 & $14.3 \%$ & \\
\hline None & 66 & $33.0 \%$ & 3 & $4.5 \%$ & 14 & $21.2 \%$ & 20 & $30.3 \%$ & 29 & $43.9 \%$ & \\
\hline \multicolumn{3}{|c|}{ Total } & 5 & $2.5 \%$ & 66 & $33.3 \%$ & 82 & $41.0 \%$ & 46 & $23.0 \%$ & \\
\hline
\end{tabular}

Table 4. Time spent engaging in physical activity after cancer diagnosis depending on time spent before diagnosis

\begin{tabular}{|c|c|c|c|c|c|c|c|c|c|c|c|c|c|c|c|}
\hline \multirow{3}{*}{$\begin{array}{l}\text { Time spent in } \\
\text { physical activity }\end{array}$} & \multicolumn{2}{|c|}{ Before diagnosis } & \multicolumn{12}{|c|}{ After diagnosis } & \multirow{3}{*}{$\begin{array}{l}\text { Wilcoxon } \\
\text { signed-rank } \\
\text { test }\end{array}$} \\
\hline & \multirow{2}{*}{$\mathbf{N}$} & \multirow[t]{2}{*}{$\%$} & \multicolumn{2}{|c|}{ None } & \multicolumn{2}{|c|}{ Up to $30 \mathrm{~min}$} & \multicolumn{2}{|c|}{$1-2$ hours } & \multicolumn{2}{|c|}{ 2-3 hours } & \multicolumn{2}{|c|}{ 3-4 hours } & \multicolumn{2}{|c|}{$\begin{array}{l}5 \text { hours and } \\
\text { more }\end{array}$} & \\
\hline & & & $\mathbf{N}$ & $\%$ & $\mathbf{N}$ & $\%$ & $\mathbf{N}$ & $\%$ & $\mathrm{~N}$ & $\%$ & $\mathbf{N}$ & $\%$ & $\mathbf{N}$ & $\%$ & \\
\hline None & 57 & $28.5 \%$ & 22 & $38.6 \%$ & 17 & $29.8 \%$ & 10 & $17.5 \%$ & 6 & $10.5 \%$ & 0 & $0.0 \%$ & 2 & $2.3 \%$ & \multirow{7}{*}{$\begin{array}{c}Z=4.42 \\
p<0.0001\end{array}$} \\
\hline Up to $30 \mathrm{~min}$ & 59 & $29.5 \%$ & 2 & $3.4 \%$ & 30 & $50.8 \%$ & 14 & $23.7 \%$ & 6 & $10.2 \%$ & 1 & $1.7 \%$ & 6 & $10.2 \%$ & \\
\hline $1-2$ hours & 46 & $23.0 \%$ & 2 & $4.3 \%$ & 10 & $21.7 \%$ & 21 & $45.7 \%$ & 8 & $17.4 \%$ & 5 & $10.9 \%$ & 0 & $0.0 \%$ & \\
\hline 2-3 hours & 16 & $8.0 \%$ & 1 & $6.3 \%$ & 1 & $6.3 \%$ & 4 & $25.0 \%$ & 8 & $50.0 \%$ & 1 & $6.3 \%$ & 1 & $6.3 \%$ & \\
\hline 3-4 hours & 12 & $6.0 \%$ & 0 & $0.0 \%$ & 0 & $0.0 \%$ & 2 & $16.7 \%$ & 3 & $25.0 \%$ & 6 & $50.0 \%$ & 1 & $8.3 \%$ & \\
\hline 5 hours and more & 10 & $5.0 \%$ & 0 & $0.0 \%$ & 2 & $20.0 \%$ & 1 & $10.0 \%$ & 1 & $10.0 \%$ & 3 & $30.0 \%$ & 3 & $30.0 \%$ & \\
\hline \multicolumn{3}{|c|}{ Total } & 27 & $13.5 \%$ & 60 & $30.0 \%$ & 52 & $26.0 \%$ & 32 & $16.0 \%$ & 16 & $8.0 \%$ & 13 & $6.5 \%$ & \\
\hline
\end{tabular}

Table 5. Leisure time activity after cancer diagnosis depending on activity before diagnosis

\begin{tabular}{|c|c|c|c|c|c|c|c|c|c|c|c|}
\hline \multirow{3}{*}{$\begin{array}{c}\text { Type of leisure time } \\
\text { activity }\end{array}$} & \multicolumn{2}{|c|}{ Before diagnosis } & \multicolumn{8}{|c|}{ After diagnosis } & \multirow{3}{*}{$\begin{array}{l}\text { Wilcoxon } \\
\text { signed-rank } \\
\text { test }\end{array}$} \\
\hline & \multirow[t]{2}{*}{$N$} & \multirow[t]{2}{*}{$\%$} & \multicolumn{2}{|c|}{ Active, low-intensity } & \multicolumn{2}{|c|}{$\begin{array}{l}\text { Active, moderate- } \\
\text { intensity }\end{array}$} & \multicolumn{2}{|c|}{$\begin{array}{l}\text { Active, high- } \\
\text { intensity }\end{array}$} & \multicolumn{2}{|c|}{ Passive } & \\
\hline & & & $\mathrm{N}$ & $\%$ & $\mathrm{~N}$ & $\%$ & $\mathbf{N}$ & $\%$ & $\mathbf{N}$ & $\%$ & \\
\hline Active, low-intensity & 89 & $44.5 \%$ & 68 & $76.4 \%$ & 5 & $5.9 \%$ & 1 & $1.1 \%$ & 15 & $16.9 \%$ & \multirow{5}{*}{$\begin{array}{c}Z=1.90 \\
p=0.0572\end{array}$} \\
\hline Active, moderate-intensity & 23 & $11.5 \%$ & 11 & $47.8 \%$ & 6 & $26.1 \%$ & 1 & $4.3 \%$ & 5 & $21.7 \%$ & \\
\hline Active, high-intensity & 3 & $1.5 \%$ & 2 & 66.75 & 1 & $33.3 \%$ & 0 & $0.0 \%$ & 0 & $0.0 \%$ & \\
\hline Passive & 85 & $42.5 \%$ & 37 & $43.5 \%$ & 6 & $7.1 \%$ & 4 & $4.7 \%$ & 38 & $44.7 \%$ & \\
\hline \multicolumn{3}{|c|}{ Total } & 118 & $59.0 \%$ & 24 & $12.0 \%$ & 6 & $3.0 \%$ & 58 & $29.0 \%$ & \\
\hline
\end{tabular}

half of the respondents spent a few hours a week engaging in it (Tab. 4).

The study also found that a large proportion of respondents who preferred to spend their leisure time in a passive way before the cancer diagnosis later preferred engaging in low-intensity physical activity.

\section{Discussion}

Physical activity is one of the modifiable elements of lifestyle which can help reduce the risk of developing breast can- cer [11]. In the case of this type of cancer, physical activity can lower the risk of remission and increase life expectancy as well. Being physically active is also important in advanced stages of the disease, as it can improve physical and mental well-being. Oncologists and other healthcare professionals should thus encourage cancer patients to engage in an adequate amount of physical activity at every stage of the disease [12, 13]. According to Hsieh et al. [14], supervised regular exercise of moderate intensity improves the function of the cardiorespiratory system as well increasing physical capacity, irrespective of the type of treatment administered. This motivated us to investigate the 
issue of engaging in sports and other physical activity before and after breast cancer diagnosis. The study showed that before developing cancer, only $18 \%$ of respondents performed regular physical activity, while as many as 33\% did not. After receiving the diagnosis, $36.5 \%$ of the women engaged in regular physical activity, and $41 \%$ did so occasionally. What is important is that a considerable proportion of the women that were surveyed spent a few hours a week performing physical activity after receiving the diagnosis. The results of our analysis are in line with those obtained by Malicka [15], whose research involved middle-aged women that had received breast cancer treatment. As many as $82 \%$ of the participants of her study declared that they spent more time engaging in recreational physical activity after the surgery than before having it. Various forms of physical activity were performed at least once a week. In a study conducted by Prokopowicz et al. [16], out of all the health behaviours investigated, the poorest results were obtained for physical activity, both in the group of healthy women and in that of former cancer patients. However, in that study, former cancer patients had better results than healthy women. Thus, the women seemed to lack the habit of performing physical activity, did not engage in it systematically, and preferred to spend their leisure time in a passive manner instead of an active one. Ridan et al. [17] carried out research on a group of women from Tarnów and Chrzanów who had undergone a single mastectomy. The mastectomy was not found to have had a significant influence on the physical activity of that group of respondents compared to the activity they engaged in before the surgery. Most respondents performed physical activity both before and after the surgical treatment with similar frequency, that is from 1 to 3 times a week.

In the current study, the analysis of the responses given regarding the leisure time activities engaged in by the respondents showed that before being diagnosed with cancer, the respondents preferred low-intensity activities (44.5\%), such as walking, gymnastics, or cycling. A considerable percentage of the women also preferred spending their leisure time in a passive way, that is sleeping, sunbathing, or reading books (42.5\%). In contrast, after developing cancer, most respondents preferred spending their leisure time in an active way, engaging in physical activity of low, moderate, or high intensity $(71 \%)$. When it comes to the findings of research carried out by other authors, Ridan et al. [17] found that undergoing a mastectomy did not have an impact on whether breast cancer patients were physically active or passive during their leisure time. In Malicka's [15] study, the activities that were the most frequently chosen by former breast cancer patients were walking, gymnastics, cycling, tourism, water exercise, swimming, and dancing; thus, these were activities of moderate intensity. The research conducted by Kachaniuk et al. [18] among cancer patients and healthy women showed, on the other hand, that the most popular way of spending free time was engaging in passive activities.

\section{Conclusions}

1. Developing breast cancer and the willingness of breast cancer patients to fight the disease can cause them to alter their health behaviour and make changes in their lifestyle in terms of the physical activity they choose to engage in.

2. Increased physical activity in women who have undergone cancer treatment can help them improve their health.

3. Women demonstrate the willpower of fighting against breast cancer, what manifests with the change of health behaviour in terms of the physical activity.

\section{Literature}

1. GLOBOCAN 2012. Estimated Cancer Incidence, Mortality and Prevalence Worldwide in 2012. Retrieved April 25, 2016, from http://globocan.iarc.fr/Pages/fact_sheets_cancer.aspx.

2. Ferlay J., Stoliarova-Foucher E., Lortet-Tieulent J., Rosso S., Coebergh J.W.W., Comber H. et al. (2013). Cancer incidence and mortality patterns in Europe: Estimates for 40 countries in 2012. European Journal of Cancer 49(6), 1374-1403.

3. Ferlay J., Soerjomataram I., Dikshit R., Eser S., Mathers C., Rebelo M. et al. (2015). Cancer incidence and mortality worldwide: Sources, methods and major patterns in GLOBOCAN 2012. International Journal of Cancer 36(5), E359-E386. DOI: 10.1002/ijc.29210.

4. Kruk J. (2006). Fruit and vegetable consumption and the risk of breast cancer. Contemporary Oncology 10(5), 224230. [in Polish]

5. Tyczyński J.E. (2003). Environmental risk factors for cancer and prevention opportunities (primary prevention). In A. Kułakowski, A. Skowrońska-Gardas (eds), Oncology. Handbook for medical students (pp. 21-27). Warszawa: PZWL. [in Polish]

6. Abdulkareem I.H. (2013). Aetio-pathogenesis of breast cancer. Nigerian Medical Journal 54(6), 371-375. DOI: 10.4103/0300-1652.126284.

7. Friedenreich C.M., Orenstein M.R. (2002). Physical activity and cancer prevention: Etiologic evidence and biological mechanisms. Journal of Nutrition 132(11), 3456-3464.

8. Kruk J. (2007). Self-reported physical activity and the risk of breast cancer. Nowotwory 57(6), 677-684. [in Polish]

9. Cigler T., Ryan P.D. (2009). Breast oncology: Clinical presentation and genetics. In B.A. Chaber, T.J. Lynch, D.L. Longo (eds), Harrison - oncology (pp. 368-374). Lublin: Czelej. [in Polish]

10. Piotrowski J. (2003). Breast cancer. In A. Kułakowski, A. Skowrońska-Gardas (eds), Oncology. Handbook for medical students (pp. 106-118). Warszawa: PZWL. [in Polish]

11. Bernstein L., Henderson B.E., Hanisch R., Sullivan-Halley J., Ross R.K. (1994). Physical exercise and reduced risk of breast cancer in young women. Journal of the National Cancer Institute 86(18), 1403-1408.

12. Litwiniuk M., Kara I. (2012). Physical activity and cancer. OncoReview 2(4), 228-233. [in Polish]

13. Pierce J., Stefanick M., Flatt S. (2007). Greater survival after breast cancer in physically active women with high vegetable-fruit intake regardless of obesity. Journal of Clinical Oncology 25(17), 2345-2351. DOI: 10.1200/JCO.2006.08.6819.

14. Hsieh C.C., Sprod L.K., Hydock D.S., Carter S.D., Hayward R., Schneider C.M. (2008). Effects of a supervised exercise intervention on recovery from treatment regimens in breast cancer survivors. Oncology Nursing Forum 35(6), 909-915. DOI: 10.1188/08.

15. Malicka I., Szczepanska-Gieracha J., Jankowska E., Wożniewski M., Rymaszewska J. (2011). Physical activity, life satisfaction, and mental adjustment to cancer in women after breast cancer treatment. Contemporary Oncology 15(3), 180-185. [in Polish]

16. Prokopowicz K., Prokopowicz G., Molik B., Kozdroń E. (2015). Assessment of selected health behaviours of women after breast cancer therapy. Postępy rehabilitacji 29(3), 5-12. [in Polish] 
17. Ridan T., Zdebska S., Ogrodzka K., Opuchlik A. (2015). Evaluation of physical activity level in women after single breast mastectomy. Problemy Higieny i Epidemiologii 9(1), 181-186. [in Polish]

18. Kachaniuk H., Stanisławek A., Bartoszek A., Kocka K., Szadowska-Szlachetka Z., Charzyńska-Gula M. (2013). An analysis of selected health behaviours of women as breast cancer risk factors. Przegląd Menopauzalny 12(6), 453-458.

Submitted: February 15, 2017

Accepted: August 8, 2017 